\section{Ensino de metodologias em Ciências Sociais e Humanas nos programas de pós-graduação em Saúde Coletiva (2002-2016)}

\author{
Teaching methodologies in Human and Social \\ Sciences in graduate studies programs in \\ Public Health (2002-2016)
}

\section{Enseñanza de metodologías en Ciencias Sociales y Humanas dentro de los programas de posgrado en Salud Colectiva (2002-2016)}

Suely Deslandes 1

Ivia Maksud 1

doi: 10.1590/0102-311X00133619

\title{
Resumo
}

As contribuições das Ciências Sociais e Humanas em Saúde (CSHS) têm sido decisivas para tratar das dinâmicas sociais que envolvem a vida, o sofrimento e o adoecimento humanos. Dessa forma, a análise da conformação do campo das CSHS tem sido tema de pesquisa de muitos autores brasileiros. Este artigo analisa a formação em CSHS (com especial foco para a formação em pesquisa) nos programas de pós-graduação em Saúde Coletiva no período de 2002 a 2016, considerando a oferta das disciplinas de CSHS e as disciplinas de formação metodológica, a partir de sua magnitude, frequência e principais influências teórico-metodológicas. Utilizamos como fonte os arquivos de "Disciplinas" e "Proposta do Programa" que integram os Cadernos de Indicadores do banco de dados da Coordenação de Aperfeiçoamento de Pessoal de Nível Superior (CAPES) e da base Sucupira. As ementas foram lidas e analisadas considerando temáticas, objetivos, obras e autores. Os dados foram registrados em planilha de Excel e analisados com auxílio do programa estatístico $R$. Os resultados mostram a estabilidade da oferta das disciplinas de CSHS (cerca de 20\% ao longo de todo período), mas modesta presença de disciplinas de metodologia em Ciências Sociais. Percebe-se diversidade de referências teórico-metodológicas, com especial destaque para obras de compilações ou textos didáticos. Destaca-se a pouca presença dos textos e dos autores clássicos das Ciências Sociais. As conclusões apontam para o desafio de transposição da formação operativa, que permite executar instrumentalmente pesquisas de alta relevância temática para a saúde, mas que pode afetar o potencial de consolidação e inovação teórica do pensamento social em saúde.

Correspondência

S. Deslandes

Departamento de Ensino, Instituto Nacional de Saúde da Mulher, da Criança e do Adolescente Fernandes Figueira Fundação Oswaldo Cruz.

Av. Rui Barbosa 716, Rio de Janeiro, RJ 22250-020, Brasil. desland@iff.fiocruz.br

1 Instituto Nacional de Saúde da Mulher, da Criança e do Adolescente Fernandes Figueira, Fundação Oswaldo Cruz, Rio de Janeiro, Brasil. 


\section{Introdução}

Neste artigo, buscamos analisar a formação em Ciências Sociais e Humanas em Saúde (CSHS), com especial foco para a formação em metodologia da pesquisa ofertada nos programas de pós-graduação em Saúde Coletiva.

Reconhecemos a Saúde Coletiva por meio das lentes interpretativas bourdianas 1,2,3 da categoria de campo, portanto, entendida como um microcosmo social dotado de leis próprias que apresenta uma estruturação e uma certa autonomia em relação a outros campos. Dessa forma, além do conjunto de práticas sociais, o campo científico que representa é também um mundo social relativamente autônomo, que organiza e se organiza a partir de capitais próprios, que proporcionarão autoridade e legitimidade cientifica aos seus agentes detentores. Trata-se de um campo de disputas em torno da legitimidade e autoridade de definir o que será estudado, com quais finalidades e de quais modos.

Para contextualizar tal proposta, começamos a partir de um breve resumo sobre a participação das Ciências Sociais no campo da Saúde Coletiva brasileira até chegar aos desafios ainda atuais de conformação de uma identidade a partir de bases disciplinares variadas, seja pela diversidade de agentes que a compõe, seja pelos desafios decorrentes da expansão e institucionalização do campo. Nosso percurso investigativo se guiou por perguntas que circulam em torno da participação das disciplinas de CSHS na formação dos quadros de pesquisa no campo da Saúde Coletiva (Como se caracteriza tal participação? Qual sua estabilidade e magnitude de oferta? Quais autores e obras são as mais preponderantes para essa formação e o que tais escolhas implicam essa formação?).

\section{As Ciências Sociais no campo da Saúde Coletiva}

A reconstituição e análise histórica da conformação do campo das Ciências Sociais em Saúde tem sido tema de pesquisa de muitos autores brasileiros 4,5,6,7. Em sua vasta obra, Everardo Nunes nos mostra como a dinâmica de interseção entre as Ciências Sociais e a Saúde traduz o percurso histórico transcorrido desde a constituição da Medicina Comunitária preventivista, Medicina Social e, posteriormente, da Saúde Coletiva. Podemos dizer que todas essas áreas de conhecimento e de práticas foram constituídas pelas Ciências Sociais em confluência (e disputas) com outros saberes.

As Ciências Sociais em Saúde desempenhavam inicialmente papel auxiliar na compreensão de uma prática clínica individual (depois alargada para níveis comunitários) e, só a partir da década de 1970, foram se delineando os contornos de uma identidade própria, especialmente a partir de lutas concorrenciais por reconhecimento científico no seio da emergente Saúde Coletiva. As Ciências Sociais em Saúde atuam, portanto, na interface de um conhecimento aplicado, atrelado ao campo empírico interno das dinâmicas da saúde e das ciências que a compõem e, por outro, precisam dialogar com as dinâmicas crítico-reflexivas das Ciências Sociais 5,8. Nunes 4 afirma que a denominação "Ciências Sociais em Saúde" tornou-se usual para aqueles que desenvolviam atividades de ensino no contexto das então chamadas áreas de Saúde Pública e Medicina Social. Posteriormente foram incorporadas disciplinas com escopos mais específicos, como Antropologia Médica, Sociologia da Saúde e Economia da Saúde.

As críticas geradas pelo pensamento social crítico latino-americano nos anos de 1970 ao modelo da medicina preventivo-comunitária, especialmente ao seu cunho funcionalista e reducionista da lógica de custo-benefício, tiveram importantes referências 4 no Seminário de Cuenca (Equador, 1972) e na obra de Juan Cesar García. A partir de então, os temas trazidos pelas Ciências Sociais mudam o foco analítico, priorizando as relações entre os modos de produção, as formações socioeconômicas e a determinação social das doenças. Dessa forma, a Medicina Social incorporou vigorosamente a leitura marxista, definindo-se pelo estudo da dinâmica do processo saúde-doença nas populações, correlacionando a estrutura de atenção médica a partir da leitura do sistema social global. A perspectiva era de um conhecimento comprometido com a transformação das relações de dominação, visando a níveis máximos possíveis de saúde e bem-estar das populações. Nesse sentido, vê-se migrar a escolha dos autores das Ciências Sociais mais presentes nessa formação preventivista (interacionistas e funcionalistas) para aqueles vinculados ao materialismo histórico 4,9.

Assim, as Ciências Sociais, especialmente a partir da escola marxista, estiveram presentes na estruturação dos primeiros programas de pós-graduação em Medicina Social no Brasil e no México, em 
meados dos anos 1970 4. Esse período demarcou uma fase reconhecida como de "institucionalização" das Ciências Sociais em Saúde 4,10. Essa institucionalização também se materializou a partir da criação de associações como o Centro Brasileiro de Estudos de Saúde (CEBES) e a Associação Brasileira de Saúde Coletiva (Abrasco), fomentando uma autorreflexão crítica dos limites e da identidade do campo (exercício nunca concluído, porque histórico e dinâmico) a partir da crise econômica, da concentração de riquezas e da supressão democrática, vigentes nos anos de 1970. O I Congresso de Ciências Sociais em Saúde, em 1995, e a consolidação e ampliação da oferta de programas de pós-graduação em Saúde Coletiva em todo o país coroam essa fase 11 .

Podemos afirmar que as leituras críticas da análise do processo social de produção de saúde embasaram o movimento sanitarista brasileiro. Todavia, as tensões entre o projeto de conhecimento das Ciências Sociais em Saúde e o projeto político "na" e "da" Saúde Coletiva sempre estiveram presentes. Cohn 12 indica a predominância de aportes macroestruturais de análise com conexões pouco mediadas pela realidade empírica, assim como a produção de um "saber militante" inteiramente comprometido com o ideário do movimento sanitário.

Contudo, o deslizamento epistêmico da categoria de saúde "das populações" para a de "saúde coletiva" traduziria a incorporação de distintos atores e conhecimentos ao campo da saúde, dispondo novos arranjos de legitimidade e poder. Birman ${ }^{13}$ pontua que a diferença da Saúde Coletiva em face do modelo da Saúde Pública é sua crítica sistemática ao postulado universalista do saber médico. A saúde é, então, relida a partir de novas coordenadas providas pelas Ciências Sociais e Humanidades, pela demarcação simbólica, ética e política de sujeitos com seus corpos que encarnam o processo da saúde e doença, em relações mediadas pela linguagem e códigos culturais, a partir de determinada tradição histórica.

O exercício intelectual do campo e as inúmeras transformações pós-globalização nas décadas de 1990 e de 2000 trouxeram diversidade temática, teórica e metodológica e uma considerável adesão aos focos individualistas e particularistas, sob a perspectiva das análises microssociológicas 5,14. Assim, os temas abarcados pelas CSHS têm variado de uma década para outra, perfazendo um corolário muito extenso, que também sofre influências das agendas de pesquisa da área de origem das Ciências Sociais 6,14,15,16,17.

Como refletem Russo \& Carrara 18, a análise histórica do percurso das Ciências Sociais no campo da Saúde Coletiva revela, portanto, duas grandes áreas de influências teórico-metodológicas e duas formas de politização do campo. A primeira, de corte marxista, permite a análise das determinações sociais do processo de produção da saúde e da doença em um contexto da produção capitalista, vinculada ao movimento sanitarista e sua agenda. A segunda, que se amplia a partir dos anos 1990-2000, está ancorada nas perspectivas socioantropológicas, em aportes compreensivistas e construtivistas, comprometidas em "dar voz" aos sujeitos, permitindo uma análise por meio das lentes da subjetividade e da cultura, modulando diferentes críticas ao modo como o modelo biomédico predomina na estruturação dos sistemas e cuidados em saúde, como se institui a medicalização da vida e as agências de resistências a esse modelo hegemônico, ultrapassando a agenda do sanitarismo.

Por fim, não há exagero em afirmar que as contribuições das categorias analíticas e das metodologias das CSHS têm sido decisivas para tratar das dinâmicas sociais que envolvem a vida, o sofrimento e o adoecimento humanos. A complexidade das relações que envolvem o processo saúde-doença-atenção, analisado pelas Ciências Sociais e Humanidades, se presentifica em cada um dos problemas contemporâneos, agudizados no processo de globalização. Por isso, esses problemas exigem criatividade e uma concepção flexível, capaz de agregar alta expertise científica em uma arena aberta ao diálogo entre saberes, com a produção de um conhecimento comprometido com o bem viver 19. Nesse cenário de parcerias e embates entre as Ciências Sociais e as demais áreas disciplinares que compõem historicamente o campo da Saúde Coletiva (Epidemiologia e Política, Planejamento e Gestão), se constitui a luta peculiar ao campo pela autonomia de fixar temas, objetos e modos próprios de análise. Se, por um lado, a Epidemiologia se constituiu historicamente como uma disciplina, cuja formação desde os anos 1950 demarca uma identidade própria e que por vezes alude ao movimento de autonomia dos programas de pós-graduação da Saúde Coletiva, já as Ciências Sociais agregam um conjunto disciplinar bem variado 18. Além das disciplinas que historicamente constituíram as Ciências Sociais na Saúde Coletiva, foram agregadas também aquelas oriundas da área de Humanas, como a Psicologia, a Psicanálise, a História, a Geografia, a Comunicação Social, a Educação e a Filosofia 11 - expandindo 
bastante suas fronteiras reflexivas, mas também dificultando uma identidade com o campo original das Ciências Sociais. Barros ${ }^{7}$ percebe uma diferença de credenciais e conhecimentos, que diz respeito tanto ao status de reconhecimento atribuído para aceitação e inserção das Ciências Sociais no campo da saúde, como à apropriação adequada das teorias, dos conceitos, dos métodos e das técnicas definidas originalmente nas Ciências Sociais. O autor, operando com esse tipo ideal, vai afirmar que as Ciências Sociais no exercício de ensino da pós-graduação em Saúde Coletiva e graduação em saúde teriam fracas credenciais, expressas na pequena participação em termos numéricos de profissionais, mas muito conhecimento, revelado pela alta quantidade de produções e por sua potência 7 . Vale refletir, considerando a diversidade de agentes em CSHS no campo da Saúde Coletiva, se as insígnias de alto conhecimento estariam disseminadas ou concentradas em alguns centros de pesquisa.

\section{As CSHS nos programas de pós-graduação de Saúde Coletiva}

As CSHS, com sua considerável expansão e crescente institucionalização ao longo das últimas décadas, agregam um grande número de praticantes (vide os milhares de participantes dos congressos em CSHS) e diversidade de agentes. Figuram os cientistas sociais com formação de uma carreira acadêmica linear na Sociologia e Antropologia que passaram a integrar o subcampo das CSHS, especialmente a partir da década de 1980; cientistas sociais que fizeram a formação de pós-graduação em programa de Saúde Coletiva; profissionais oriundos das carreiras de saúde que cursaram a pós-graduação em Antropologia ou Sociologia; e, por fim, representando o maior contingente dos agentes das CSHS, os profissionais da saúde que se tornam "praticantes" das CSHS ou do vasto campo denominado de "pesquisa social". São profissionais de saúde (enfermeiros, nutricionistas, médicos, fonoaudiólogos, assistentes sociais, dentistas, dentre tantas outras categorias) que elegeram temas de estudo cuja imbricação com as CSHS os levou ao desafio enorme de dominar uma expertise científica distinta da de sua formação de origem. Tamanha diversidade de background no domínio teórico-metodológico do campo das Ciências Sociais acaba por delegar à formação em pós-graduação na Saúde Coletiva um importante papel na inculcação dos "modelos de percepção e estruturas mentais" - ou habitus desse campo científico, mas também instaura desafios sobre qual tipo de formação será priorizada, quais pontes serão construídas entre vivências e práxis científicas e quais competências acadêmicas serão necessárias.

As teorias que embasam as disciplinas do campo e seus respectivos aportes epistêmico-metodológicos são importantes matrizes de percepção a conformar o habitus científico pois se apresentam como "um programa de percepção e de ação só revelado no trabalho empírico que realiza" 20 (p. 59). Da mesma forma, são domínios constituintes do habitus científico a apropriação do conhecimento em metodologia, do saber decidir sobre a adequação do método ao objeto e ao propósito investigativo, bem como as condições de seu emprego, ou seja, saber pôr em ação os modos de apreciação e julgamento teórico para a produção de pesquisa.

A inculcação do habitus científico se faz privilegiadamente pela ação pedagógica das instituições e dos agentes reconhecidos pelo campo como aptos a tal mister. Destaca-se aí, em primeiro lugar, o papel do sistema de ensino, sob a forma do aprendizado formal das disciplinas ${ }^{3}$. Contudo, não podemos nos esquecer de mencionar o papel vigoroso de uma "pedagogia do silêncio", ou seja, do ensino das posturas e soluções práticas realizadas no processo real de produção de investigação e conhecimento científico que se apresentam na resolução dos problemas cotidianos da pesquisa 3 . Essas formas de inculcação passam ainda pela observação das práticas, seja nas dinâmicas do fazer a pesquisa, nas conversas formais e informais, seja nas performances institucionais. Também desempenham importante papel as instituições encarregadas de julgamento e difusão seletiva das obras acadêmicas, tais como as revistas científicas, que operam a partir dos critérios dominantes da ciência oficial (reconhecida como portadora de qualidades científicas), e não raro censuram as produções vistas como "heréticas" 2,21.

Contudo, como discutem diversos pesquisadores 5,14,22,23,24,25,26, o uso das teorias e metodologias das Ciências Sociais na produção científica em Saúde Coletiva tem sido marcado pelas seguintes práticas: emprego reificado das categorias êmicas; análises eminentemente descritivas e sem interlocução com teorias; exaustiva repetição dos mesmos métodos e técnicas, nem sempre coerentes com 
os objetivos investigativos; confusão entre o estatuto do método e das técnicas; e desconhecimento de preceitos epistêmicos fundamentais das disciplinas que sustentam tais aportes.

Tal quadro revela alguns paradoxos. O primeiro e mais evidente é que, apesar da presença fundante das Ciências Sociais no campo da Saúde Coletiva e sua expansão, especialmente após a década de 1990, não parece ter havido ainda uma apropriação suficiente das teorias, metodologias e, sobretudo, das lógicas epistêmicas das Ciências Sociais que sustentam o subcampo das CSHS 22. Isso permite supor que, apesar do considerável número de programas de pós-graduação que incluem as CSHS no seu projeto de formação, não se tem conseguido formar o desejado habitus científico no exercício dessas ciências. Isso nos leva a perguntar: como tem sido a incorporação dessas disciplinas nas grades curriculares da pós-graduação?

Considerando tais questionamentos, nosso artigo visa analisar a formação em CSHS (com especial foco para a formação em pesquisa) nos programas de pós-graduação em Saúde Coletiva no período de 2002 a 2016. Analisamos a oferta das disciplinas de CSHS e as disciplinas de formação metodológica na grade curricular, levando em conta a magnitude, a frequência e as principais influências, balizadas pelas referências utilizadas (autores e linhagens teórico-metodológicas).

\section{Metodologia}

A identificação das disciplinas de Ciências Sociais e CSHS ofertadas pelos programas de pós-graduação estrito senso em Saúde Coletiva (mestrado acadêmico e doutorado) foi feita a partir da consulta aos arquivos de "Disciplinas" e "Proposta do Programa" que integram os Cadernos de Indicadores do banco de dados da Coordenação de Aperfeiçoamento de Pessoal de Nível Superior (CAPES) e da base Sucupira. A caracterização geral da participação das CSHS na totalidade das disciplinas ofertadas compreendeu o período de 2002 a 2012. A análise das disciplinas de metodologia de Ciências Sociais incluiu os anos de 2002-2012 e o quadriênio de 2013-2016.

Foram lidas uma a uma as ementas das disciplinas ofertadas pela totalidade dos programas acadêmicos de Saúde Coletiva e selecionadas aquelas cujos conteúdos foram identificados como de CSHS, considerando temáticas, objetivos, obras e autores. Incluímos as disciplinas do tronco de Ciências Sociais (Antropologia e Sociologia) e as disciplinas de Humanas (História, Psicologia/Psicanálise, Filosofia, Ética/Bioética). As disciplinas de Ciências Políticas e de Economia, historicamente vinculadas ao subcampo de Política, Planejamento e Gestão foram classificadas nesse domínio (Política, Planejamento e Gestão), e não consideradas nessa análise.

A classificação das disciplinas foi feita de forma independente por três cientistas sociais, todas com doutorado em Saúde Coletiva. Cada classificação foi revisada por uma segunda avaliação e, em caso de discordância, a terceira avaliação foi decisiva. Para o presente artigo, focamos a formação oferecida no campo das metodologias de Ciências Sociais. Uma disciplina pode ter sido repetida ao longo dos anos, tendo sido considerada a cada vez que foi ofertada.

Os dados foram registrados em planilha de Excel (https://products.office.com/), onde constavam o ano, o nome do programa, o número total de disciplinas oferecidas pelo programa, a distribuição das disciplinas segundo a área de pertencimento (CSHS, Epidemiologia, Política, Planejamento e Gestão, outras) e seu status (obrigatória ou eletiva). Para o conjunto das disciplinas de metodologia em Ciências Sociais, além dessas variáveis, foram identificados ainda o seu título, os professores responsáveis, os autores e as obras indicadas (artigos, livros ou capítulos).

As disciplinas de métodos analisadas apresentaram designações diversas ("metodologias qualitativas", "métodos em pesquisa social", "métodos não estruturados" ou métodos específicos das Ciências Sociais tais como "método etnográfico", "análise de discurso", "análise quantitativa em Ciências Sociais" etc.). Não foram considerados nesse rol os seminários avançados ou aquelas disciplinas exclusivamente voltadas para elaboração e acompanhamento de projetos (denominadas por nós como disciplinas instrumentais), ainda que em algumas delas fossem identificados conteúdos vinculados à formação de pesquisa em Ciências Sociais. Foram analisados a distribuição percentual de disciplinas e o número de referências recebidas pelos autores, além das obras citadas nas ementas. Destacamos que um mesmo autor pode ter sido mencionado mais de uma vez em uma mesma ementa. Contabilizamos a primeira autoria de cada obra. Por último, analisamos como se distribuíram os autores citados, 
por meio da técnica de nuvem de palavras (TNP), que permite a visualização de dados segundo um conjunto de palavras, como um gráfico de dispersão, cujo tamanho de cada palavra é proporcional à sua frequência no texto de onde foi extraída. O programa estatístico utilizado para as análises foi o R, versão 3.5.1 (http://www.r-project.org). Para a análise, só foram considerados autores com uma frequência maior do que dez citações.

\section{Resultados e discussão}

A distribuição temporal do número de programas em Saúde Coletiva mostrou um crescimento considerável no período de 2002 a 2016 (Tabela 1). Em 2002, eram 23 programas acadêmicos e, em 2012, já se contavam 40. Assim, o montante das disciplinas oferecidas mais que duplica nesse percurso. As disciplinas de "outras áreas/multidisciplinares" tiveram presença cada vez mais significativa e com maior crescimento percentual, incluindo um leque bastante variado (com destaque para Biomédicas, Ambiente e Nutrição), além de disciplinas temáticas de cunho inter ou multidisciplinar (com participação compartilhada entre diversas áreas de conhecimento, inclusive CSHS, Epidemiologia, e Política, Planejamento e Gestão). Tal configuração parece indicar que a clássica distribuição dos três subcampos (CSHS, Epidemiologia e Política, Planejamento e Gestão) já não é suficiente para retratar o campo da Saúde Coletiva em seus múltiplos arranjos disciplinares e epistêmicos.

Há dez anos, Nunes et al. 27 demonstravam como a Saúde Coletiva já se caracterizava pela coexistência e multiplicação de saberes e práticas. Analisando a relação de disciplinas obrigatórias e eletivas de cursos de pós-graduação em Saúde Coletiva em 2006, disponíveis nos registros da CAPES, os autores as classificam em 29 campos disciplinares, com destaque para Epidemiologia, CSHS, Didática, Sistemas e Serviços de Saúde, Ambiente e Saúde, e Políticas de Saúde.

A maciça oferta de disciplinas de Epidemiologia se apresenta constante em todo o período, confirmando sua hegemonia na formação dos pesquisadores e no campo político e científico da Saúde Coletiva. As bases de sua hegemonia, demarcadas desde a década de 1990, já foram exaustivamente discutidas, seja pela adoção de modelos avaliativos de ciência e tecnologia que valorizam seus modos de produção acadêmica, seja pela ocupação de posições estratégicas na definição política dos critérios de regulação da produção científica do campo 9,18,28.

Tabela 1

Caracterização das disciplinas em programas de pós-graduação acadêmicos estrito senso da Saúde Coletiva segundo áreas disciplinares, 2002-2012.

\begin{tabular}{lcccc}
\hline Ano & $\begin{array}{c}\text { Programas } \\
\text { acadêmicos }\end{array}$ & Disciplinas ofertadas & Disciplinas de CSHS & $\begin{array}{c}\text { Disciplinas } \\
\text { instrumentais * }\end{array}$ \\
\hline 2002 & 23 & 812 & 169 & 101 \\
2003 & 26 & 1.011 & 199 & 105 \\
2004 & 27 & 1.068 & 203 & 109 \\
2005 & 27 & 1.095 & 205 & 163 \\
2006 & 28 & 1.182 & 227 & 152 \\
2007 & 31 & 1.316 & 260 & 196 \\
2008 & 34 & 1.423 & 263 & 209 \\
2009 & 37 & 1.537 & 281 & 241 \\
2010 & 38 & 1.616 & 316 & 283 \\
2011 & 39 & 1.713 & 334 & 272 \\
2012 & 40 & 1.793 & 322 & 298 \\
\hline
\end{tabular}

CSHS: Ciências Sociais e Humanas em Saúde.

* Disciplinas com foco instrumental para elaborar/acompanhar o projeto, redigir trabalhos científicos, elaborar apresentações, realizar busca bibliográfica, manejar equipamentos ou softwares. 
Na Figura 1, pode-se ver que a distribuição percentual de disciplinas de Humanas oscila ao longo do período de 2002-2012, terminando em declínio em relação a 2002. A composição das disciplinas de Ciências Sociais e de Humanas pouco varia e, exceto em 2002, não ultrapassa o percentual de 20\% das disciplinas oferecidas. Das disciplinas de Humanas, a Filosofia se destaca com a maior oferta de disciplinas (327), a Psicologia/Psicanálise com 317, a Bioética com 218 e a História com a menor oferta (43).

No que concerne à formação em metodologia em CSHS, tomando o período de 2002-2016, encontramos dois tipos de disciplinas: (a) as disciplinas multidisciplinares que apresentavam abordagens introdutórias tanto de métodos epidemiológicos como qualitativos; e (b) as disciplinas inteiramente dedicadas aos diferentes métodos das CSHS.

Foram ofertadas 572 disciplinas de métodos multidisciplinares, variando entre 25 disciplinas em 2002, 65 em 2012 e 37 em 2016. No período de 2012 a 2016, foram oferecidas 963 disciplinas de métodos de CSHS, oscilando de 47 (2002) a 87 (2012) e culminado com 73 em 2016. A análise dos dois tipos de disciplinas nos sugere que houve um entendimento crescente quanto à necessidade de disciplinas com mais especificidade em CSHS do que das generalistas multimétodos.

Todavia, considerando a distribuição das disciplinas de métodos de CSHS por programas, observamos na Figura 2 que predominou a oferta de apenas uma disciplina por ano. Em 2002, sete programas e, em 2016, mais da metade dos programas (25) apresentavam esse baixíssimo nível de oferta. A ausência de disciplinas de métodos de CSHS foi observada em quatro programas em 2002, em sete em 2014 e em dois programas em 2016. Como era de se esperar, os programas compostos de três subcampos da Saúde Coletiva (Epidemiologia, Política, Planejamento e Gestão, e CSHS) e com maior número de docentes foram os que apresentaram estabilidade da oferta e um número maior de disciplinas de métodos de CSHS por ano, destacando-se os programas de Saúde Pública da Fundação Oswaldo Cruz (Fiocruz), os de Saúde Coletiva do Instituto de Medicina Social da Universidade do Estado do Rio de Janeiro (UERJ), da Universidade Estadual de Campinas (UNICAMP), da Universidade Estadual

\section{Figura 1}

Distribuição percentual das disciplinas de Ciências Sociais, Humanas e outras, 2002-2012.

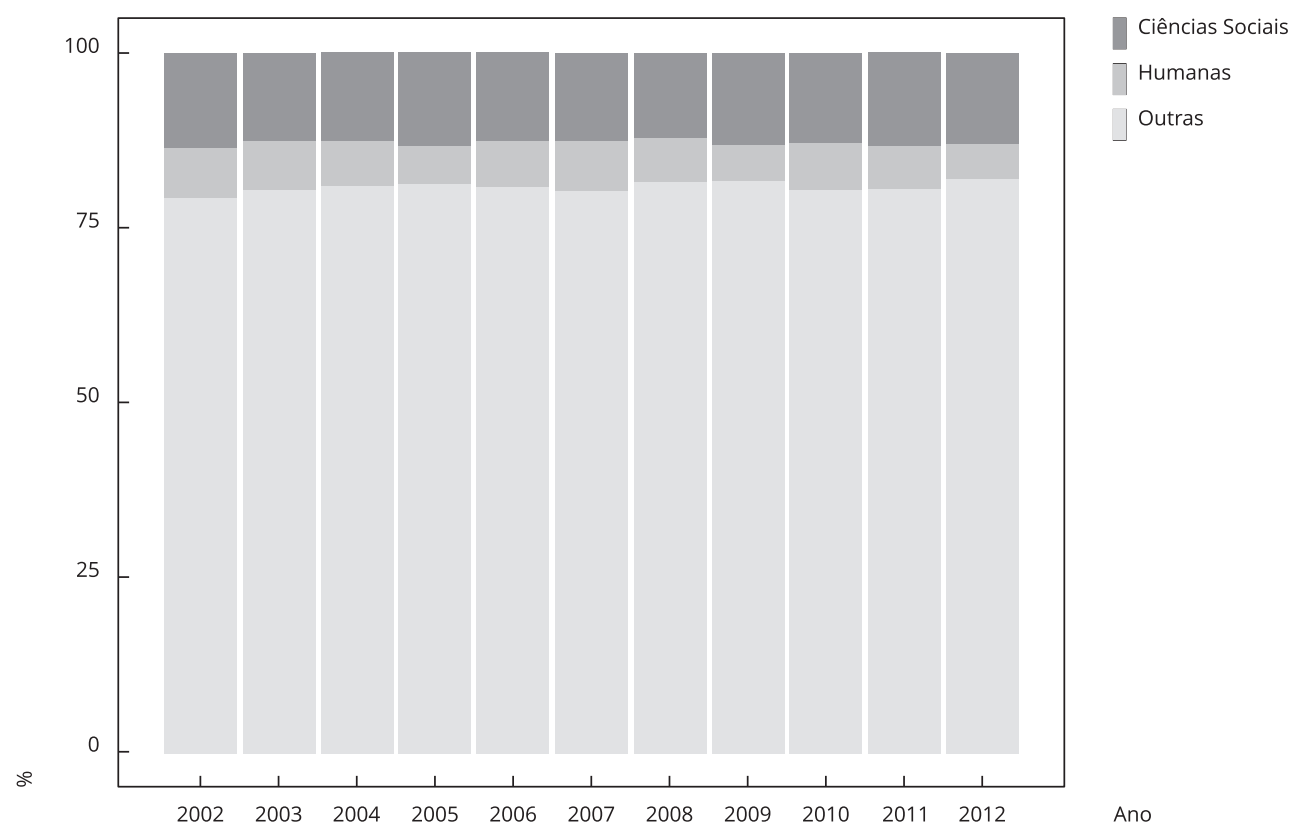




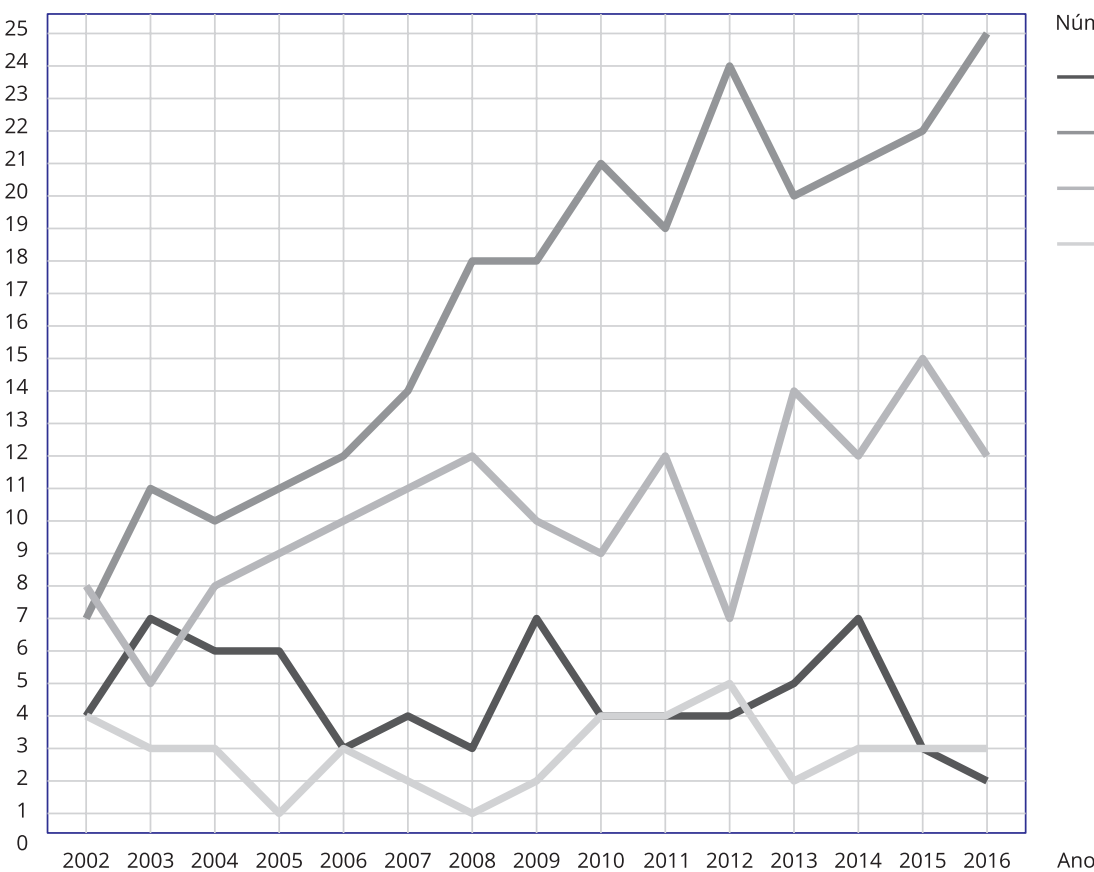

Número de disciplinas

$20022003200420052006200720082009201020112012 \quad 2013201420152016$

do Ceará (UECE), do Instituto de Saúde Coletiva da Unviersidade Federal da Bahia (UFBA) e, mais recentemente, do programa de Saúde Pública da Universidade de São Paulo (USP).

Considerando as disciplinas de métodos de CSHS oferecidas entre 2002 a 2016, verificamos a presença de 1.571 diferentes autores (Figura 3), o que revela evidente riqueza e diversidade de referências teórico-metodológicas. Em contrapartida, foram identificadas 408 obras citadas por mais de dez vezes ao longo do período analisado, indicando um círculo mais restrito das obras que se mostram constantes e influentes na formação.

Dentre os vinte autores mais citados na condição de primeiro autor, foi observada a inequívoca liderança de Maria Cecília de Souza Minayo como a mais referenciada nas disciplinas de métodos de CSHS (887 citações), seguida por Howard Becker (238), Pedro Demo (227), Laurence Bardin (217), Norman Denzin (197), Pierre Bourdieu (187), Clifford Geertz, (176), Ulrich Flick (157), Augusto Trivinos (149), Maria Teresa Haguete (143), Michel Thiollent (140), Maria Lúcia Bosi (120), Suely Deslandes (118), Denise Jodelet (117), Francisco Mercado (115), o epidemiologista Cesar Víctora (113), Fernando Lefèvre (111), Edgar Morin (88), Boaventura de Sousa Santos (88) e Mary Jane Spink (87).

Estendendo aos 50 primeiros autores mais citados, percebemos a preferência pelos que apresentam obras de compilações ou textos didáticos sobre as abordagens teórico-metodológicas fundadoras do campo das Ciências Sociais. Nesse extrato, apenas 17 eram os criadores das abordagens consagradas na Sociologia e Antropologia. Bronislaw Malinowski, por exemplo, ocupou o 32o lugar com 73 citações e Claude Lévi-Strauss o 44o posto, com 58 citações. O autor clássico do método interacionista simbólico, Erving Goffman, recebeu 48 citações.

Os autores considerados os pilares das Ciências Sociais pouco estiveram presentes nessa formação. Pensando o materialismo dialético, Karl Marx recebeu apenas 48 citações nos 15 anos analisados. Émile Durkheim recebeu apenas 37 citações e Max Weber somente 25 citações, ocupando a 134a posição dentre os autores citados. No campo das referências epistemológicas citadas nas ementas 


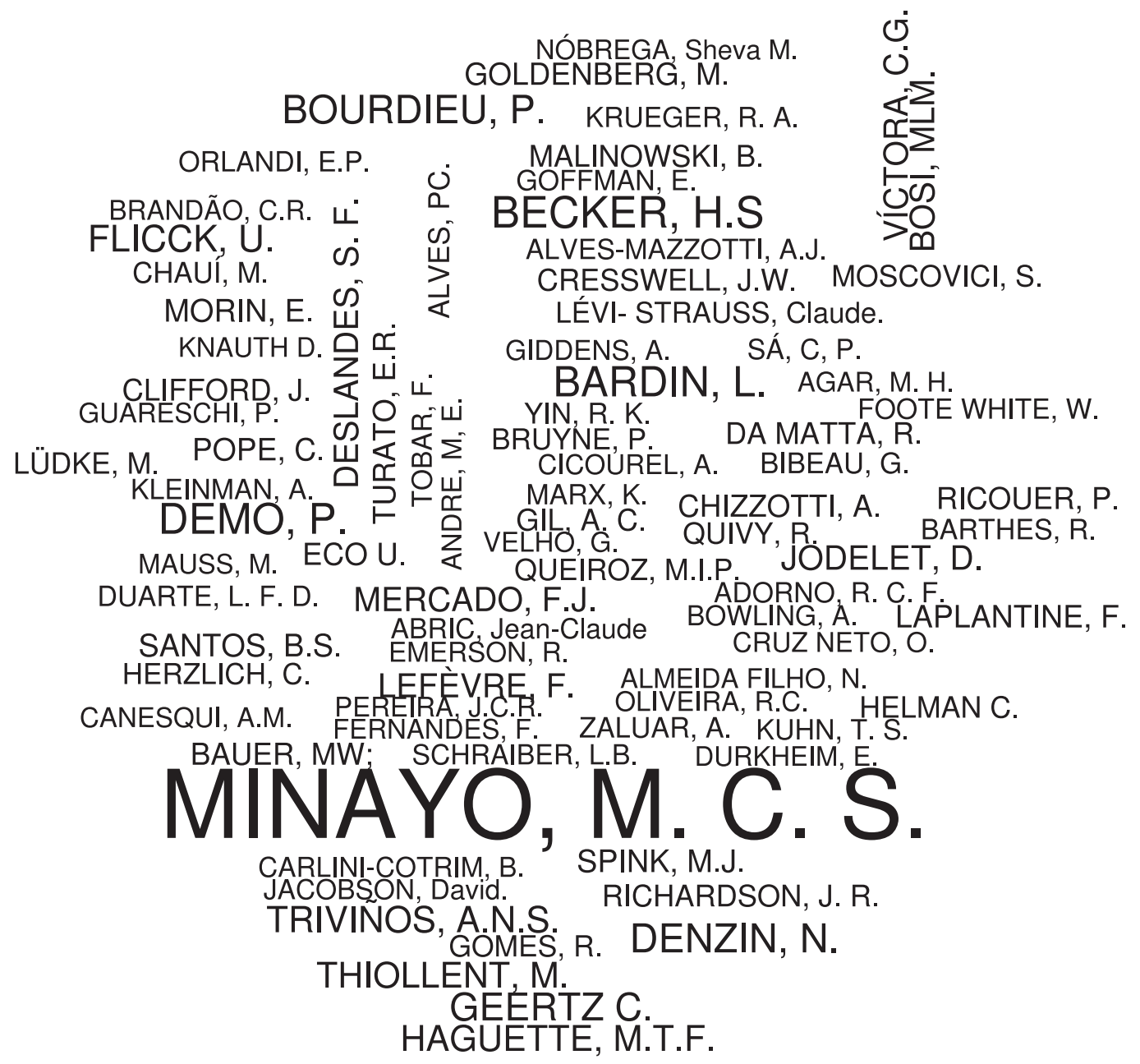

de metodologia, o brasileiro Pedro Demo recebeu 227 menções, Edgar Morin e Boaventura de Sousa Santos receberam 88 citações cada, Paul de Bruyne 60, Thomas Kuhn 49, Hilton Japiassu 35, Georges Canguilhem 27, Bruno Latour 18, Henri Lefebvre e Karl Popper receberam 13 e Gaston Bachelard apenas 10.

Dentre as obras mais citadas (Tabela 2) está a obra seminal da professora Cecília Minayo, O Desafio do Conhecimento, lançado em 1992, seguida pelo clássico livro de Bardin, lançado no Brasil em 1979 que virou o ícone da análise de conteúdo. Vale destacar a sinergia dessas duas obras, posto que o "Desafio do Conhecimento" toma o livro "Análise de Conteúdo" como uma referência para análise, sugerindo sua leitura. Tais dados ajudam a compreender a predominância da análise de conteúdo nas pesquisas de cunho qualitativo na Saúde Coletiva, quase que unicamente em sua modalidade temática, como já demonstrado em outros estudos 23 . Todavia, na mesma obra de Minayo, se apresenta uma profunda discussão epistêmica sobre os quadros analíticos da hermenêutica e dialética, com referência a autores clássicos como Jürgen Habermas e Hans-Georg Gadamer, que pouco foram citados nas ementas de métodos de CSHS. 


\section{Tabela 2}

Cinquenta obras mais citadas nas ementas de metodologia em Ciências Sociais e Humanas em Saúde nos programas de pós-graduação em Saúde Coletiva, 2002-2016.

\begin{tabular}{|c|c|c|}
\hline Obra & Autor(a) & Citações \\
\hline O Desafio do Conhecimento: Pesquisa Qualitativa em Saúde & Minayo MCS & 426 \\
\hline Análise de Conteúdo & Bardin L & 217 \\
\hline Métodos de Pesquisa em Ciências Sociais & Becker HS & 178 \\
\hline Handbook of Qualitative Research & Denzin N, Lincoln Y & 158 \\
\hline Metodologias Qualitativas na Sociologia & Haguette MTF & 135 \\
\hline Introdução à Pesquisa em Ciências Sociais: A Pesquisa Qualitativa em Educação & Triviños ANS & 134 \\
\hline Pesquisa Social: Teoria, Método e Criatividade & Minayo MCS, Deslandes SF, Gomes R & 132 \\
\hline Pesquisa Qualitativa em Saúde: Uma Introdução ao Tema & Victora CG, Knauth DR, Hassen MNA & 107 \\
\hline A Interpretação das Culturas & Geertz C & 99 \\
\hline Quantitativo-Qualitativo: Oposição ou Complementaridade? (artigo) & Minayo MCS, Sanches O & 95 \\
\hline Metodologia do Conhecimento Científico & Demo P & 88 \\
\hline Uma Introdução à Pesquisa Qualitativa & Flick U & 88 \\
\hline A Arte de Pesquisar. Como Fazer Pesquisa Qualitativa em Ciências Sociais & Goldenberg M & 79 \\
\hline Pesquisa em Ciências Humanas e Sociais & Chizzotti A & 78 \\
\hline O Discurso do Sujeito Coletivo. Uma Abordagem Metodológica em Pesquisa Qualitativa & Lefévre F, Lefévre AMC, Teixeira JJV & 78 \\
\hline Pesquisa Qualitativa de Serviços de Saúde & Bosi MLM, Mercado FJ & 73 \\
\hline $\begin{array}{l}\text { Os Argonautas do Pacífico Ocidental. Um Relato do Empreendimento e da Aventura } \\
\text { dos Nativos nos Arquipélagos da Nova Guiné Melanésia }\end{array}$ & Malinowski B & 72 \\
\hline Pesquisa Social: Métodos e Técnicas & Richardson RJ et al. & 72 \\
\hline Cultura, Saúde e Doença & Helman C & 67 \\
\hline Manual de Investigação em Ciências Sociais & Quivy R, Van Campenhoudt L & 65 \\
\hline Metodologia da Pesquisa-Ação & Thiollent M & 61 \\
\hline Pesquisa Qualitativa na Atenção à Saúde & Pope C, Mays N & 60 \\
\hline Pesquisa Qualitativa, com Texto, Imagem e Som & Bauer MW, Gaskell G & 57 \\
\hline Representações Sociais: Um Domínio em Expansão? (artigo) & Jodelet D & 57 \\
\hline Dinâmica da Pesquisa em Ciências Sociais & Bruyne P, Herman J, Schoutheete M & 56 \\
\hline $\begin{array}{l}\text { Tratado da Metodologia da Pesquisa Clínico-Qualitativa: Construção Teórico- } \\
\text { Epistemológica Comparada e Aplicação nas Áreas de Saúde e Humanas }\end{array}$ & Turato ER & 55 \\
\hline Como Se Faz Uma Tese & Eco U & 53 \\
\hline Estudo de Caso: Planejamento e Métodos & Yin RK & 52 \\
\hline Pesquisa em Educação: Abordagens Qualitativas & Lüdke M, André MEDA & 51 \\
\hline Métodos e Técnicas de Pesquisa Social & Gil AC & 49 \\
\hline A Estrutura das Revoluções Científicas & Kuhn TS & 48 \\
\hline Avaliação por Triangulação de Métodos & Minayo MCS, Assis SG, Souza ER & 48 \\
\hline Ciência com Consciência & Morin E & 48 \\
\hline Caminhos do Pensamento. Epistemologia e Método & Minayo MCS, Deslandes SF & 47 \\
\hline O Poder Simbólico & Bourdieu P & 46 \\
\hline Crítica Metodológica, Investigação Social e Enquete Operária & Thiollent M & 46 \\
\hline $\begin{array}{l}\text { Abordagens Quantitativa e Qualitativa em Saúde: Um Diálogo das Diferenças (capítulo } \\
\text { do livro Caminhos do Pensamento. Epistemologia e Método) }\end{array}$ & Deslandes SF, Assis SG & 44 \\
\hline Reading Ethnography & Jacobson D & 44 \\
\hline Introdução a Uma Ciência Pós-Moderna & Santos BS & 44 \\
\hline Como Fazer Teses em Saúde Pública & Tobar F, Romano M & 44 \\
\hline $\begin{array}{l}\text { Potencialidades da Técnica Qualitativa Grupo Focal em Investigações sobre Abuso de } \\
\text { Substâncias (artigo) }\end{array}$ & Carlini-Cotrim B & 43 \\
\hline A Problemática da Representação Social e sua Utilidade no Campo da Doença (artigo) & Herzlich C & 43 \\
\hline
\end{tabular}

(continua) 
Tabela 2 (continuação)

\begin{tabular}{|c|c|c|}
\hline Obra & Autor(a) & Citações \\
\hline Focus Group: A Practical Guide for Applied Research & Krueger RA & 43 \\
\hline Writing Ethnographic Fieldnotes & Emerson RM, Fretz RI, Shaw LL & 41 \\
\hline Projeto de Pesquisa: Métodos Quantitativo, Qualitativo e Misto & Creswell JW & 40 \\
\hline O Método nas Ciências Naturais e Sociais: Pesquisa Quantitativa e Qualitativa & Alves-Mazzotti AJ & 39 \\
\hline Teoria e Método em Pesquisa de Campo (capítulo do livro Desvendando & Cicourel A & 39 \\
\hline \multicolumn{3}{|l|}{ Máscaras Sociais) } \\
\hline Aprender Antropologia & Laplantine F & 39 \\
\hline Representações Sociais & Moscovici S & 39 \\
\hline $\begin{array}{l}\text { Análise de Dados Qualitativos. Estratégias Metodológicas para as Ciências da Saúde, } \\
\text { Humanas e Sociais }\end{array}$ & Pereira JCR & 39 \\
\hline
\end{tabular}

Poucas obras clássicas do aprendizado teórico-metodológico em Antropologia são mencionadas, com ênfase para os textos A Interpretação das Culturas e Os Argonautas do Pacífico Ocidental. No campo das obras consagradas da Sociologia, há destaque apenas para a perspectiva acionalista das obras de Michel Thiollent. Pierre Bourdieu comparece com a obra O Poder Simbólico, mas notamos a presença mais discreta dos trabalhos que notabilizaram sua reflexão epistêmica e metodológica, como O Ofício do Sociólogo (32 citações).

A preferência pelos textos de compilação se apresenta de forma evidente, o que pode indicar uma escolha visando a maior inclusão em face da diversidade de formações disciplinares dos alunos de Saúde Coletiva, com forte presença daqueles oriundos das biomédicas. Trata-se de um esforço "introdutório" que caberia aos orientadores dar continuidade e aprofundamento com seus pupilos, a partir de percursos individualizados e voltados para a natureza de seus objetos. Todavia, pode também configurar uma perspectiva delimitada por um domínio mais instrumental voltado à execução de pesquisas, identificado com um uso "aplicado" das Ciências Sociais, como têm defendido outros estudiosos do tema 5,22,24,25,26.

Ferreira \& Brandão ${ }^{29}$, em recente reflexão sobre ensino e aprendizagem de teoria e metodologia de etnografias em saúde, atestam que profissionais de saúde de distintas origens disciplinares têm passado pela formação de fundamentos teórico-metodológicos da pesquisa em Ciências Sociais na Saúde Coletiva, mas problematizam a instrumentalização dessa formação, com forte enfoque operacional.

Mais uma vez ressaltamos que a formação de um habitus não se dá apenas por meio do ensino formal de disciplinas ${ }^{3}$. Assim, a práxis da pesquisa, a participação em fóruns de apresentação acadêmica, o convívio com os orientadores e o aprendizado empírico das estratégias para consolidar posições de prestígio científico são elementos fundamentais a serem investigados.

\section{Considerações finais}

Nosso estudo encontrou as inevitáveis dificuldades de atribuir classificações que "etiquetem" as ementas que muitas vezes escapam às definições prévias, seja pela riqueza do diálogo que estabelecem em seu interior com outros campos de conhecimento, seja por estarem nas fronteiras das filiações disciplinares. As ementas também nem sempre são devidamente atualizadas pelos docentes a cada ano, portanto a análise do acervo desse material não garante um retrato totalmente fiel ao que efetivamente é trabalhado com os discentes. A análise dos conteúdos programáticos das disciplinas também seria tarefa importante para aprofundar o debate. Acreditamos que o presente estudo não dá conta de muitas outras questões que afetam o tema, como a imbricação entre ensino e pesquisa, assim como da formação em teoria social e suas implicações na formação metodológica, mas contribui por seu caráter exploratório e por aportar dados que nos permitem problematizar a formação em pesquisa social que tem sido ofertada pelo campo da Saúde Coletiva. 
Como vimos, a formação em CSHS no campo da pós-graduação em Saúde Coletiva se mostrou constante e presente na quase totalidade dos programas. Porém, predomina na pós-graduação, que constitui a mais alta esfera de formação de pesquisadores, uma modesta oferta de disciplinas de metodologias em Ciências Sociais e com pouco destaque para as obras e autores clássicos, além de discreta presença de literatura que permita a reflexão epistemológica dessas disciplinas de origem. A discreta presença dos autores clássicos da área de Ciências Sociais na formação para pesquisa dificulta o acesso direto e crítico aos legados teórico-metodológicos essenciais para o pensamento social 30. Da mesma maneira, há falta de perspectivas contemporâneas da pesquisa social atentas às modificações da ordem social mundial pós-globalização e de suas intersubjetividades, como as leituras pós-modernas das vertentes que convocam o pesquisador como ator da história com suas memórias, vivências e corporalidades, bem como metodologias que se dedicam a lidar com as novas fronteiras sociotecnológicas presentificadas nos mundos de socialidade digital.

Se o domínio científico disciplinar é reconhecido como uma condição para o bom exercício da reflexão interdisciplinar, a formação de maior natureza operativa e instrumental pode minar o projeto de reflexão guiado pela perspectiva da complexidade, característico do ideário da Saúde Coletiva. Pode ainda levar a um espaço subordinado de reflexão, afinal, na Saúde Coletiva, como em qualquer campo científico, o domínio do habitus científico funciona também como um haver, um capital, em um campo de disputas pelo exercício de autonomia de definição entre quais objetos serão eleitos e a partir de quais enfoques metodológicos serão abordados 31. Assim, a formação que pouco consolida tal capital científico pode conduzir a uma posição frágil, seja no campo interno da Saúde Coletiva, seja no campo ampliado das Ciências Sociais com o qual busca dialogar, mas sobretudo constitui um desperdício de imenso potencial das reflexões e intervenções que podem ser produzidas por esses pesquisadores.

Discutir a formação das CSHS demanda refletir sobre nossas expectativas. Parece haver um certo acordo de que se busca formar um profissional que traz uma bagagem preciosa de experiências acumuladas nos serviços e gestão de saúde e que transitará entre os conhecimentos e epistemes do biológico e do social. Acreditamos que o desafio é o de transpor a formação operativa, que permite executar instrumentalmente pesquisas de alta relevância temática para a saúde, mas cujos objetos são delimitados sem a construção e problematização dos arcabouços teórico-metodológicos das Ciências Sociais. Tal modelo permite cumprir os requisitos de produtividade, expressos no alto contingente de publicações, e traduz um avanço nos estudos exploratórios. Todavia, deixa de cumprir todo seu potencial para a consolidação e inovação teórica do pensamento social em saúde. 


\section{Colaboradores}

S. Deslandes coordenou a pesquisa e realizou a coleta e análise de dados e a redação do artigo. I. Maksud realizou a coleta e análise de dados e colaborou na redação do artigo.

\section{Informações adicionais}

ORCID: Suely Deslandes (0000-0002-7062-3604); Ivia Maksud (0000-0002-3465-151X).

\section{Agradecimentos}

Pesquisa realizada com apoio do Conselho Nacional de Desenvolvimento Científico e Tecnológico (CNPq; processo 307694/2015-1) e com apoio da Fundação de Amparo à Pesquisa do Rio de Janeiro (FAPERJ). Ruth Britto colaborou na longa etapa de coleta de dados.

\section{Referências}

1. Bourdieu P. O campo científico. In: Ortiz R, organizador. Pierre Bourdieu: sociologia. São Paulo: Editora Ática; 1983. p. 122-55. (Coleção Grandes Cientistas Sociais).

2. Bourdieu P. A economia das trocas simbólicas. São Paulo: Perspectiva; 1987.

3. Bourdieu P. O poder simbólico. Rio de Janeiro: Bertrand Brasil; 2009.

4. Nunes ED. As Ciências Sociais em Saúde: reflexões sobre as origens e a construção de um campo de conhecimento. Saúde Soc 1992; 1:59-84.

5. Cohn A. Ciências sociais e saúde pública/coletiva: a produção do conhecimento na sua interface. Saúde Soc 2013; 22:15-20.

6. Ianni AMZ. O campo temático das ciências sociais em saúde no Brasil. Tempo Soc 2015; 27:13-32.

7. Barros NF. O ensino das ciências sociais em saúde: entre o aplicado e o teórico. Ciênc Saúde Colet 2014; 19:1053-63.

8. Minayo MCS. Herança e promessas do ensino das Ciências Sociais na área da Saúde. Cad Saúde Pública 2012; 28:2367-72.

9. Loyola MAR. A saga das Ciências Sociais na área da Saúde Coletiva: elementos para reflexão. Physis (Rio J.) 2008; 18:251-75.

10. Mercer H. As contribuições da Sociologia à pesquisa em saúde. In: Nunes ED, organizador. As ciências sociais em saúde na América Latina. Tendências e perspectivas. Brasília: Organização Pan-Americana da Saúde; 1985. p. 221-34.

11. Ianni AMZ, Spadacio C, Barboza R, Alves OSF, Viana SDL, Rocha AT. Trajetórias profissionais na constituição das Ciências Sociais e Humanas em Saúde na Abrasco. Physis (Rio J.) 2014; 24:1315-36

12. Cohn A. Conhecimento e prática em saúde coletiva: o desafio permanente. Saúde Soc 1992; 1:97-109.

13. Birman J. A Physis da saúde coletiva. Physis (Rio J.) 2005; 15 Suppl:11-6.

14. Trad LAB. Temas e enfoques contemporâneos nas Ciências Sociais e Humanas no Brasil: expressões e tendências refletidas no $\mathrm{V}$ congresso da área. Cad Saúde Pública 2012; 28:2373-9.

15. Marsiglia RGM, Spinelli SP, Lopes MF, Silva TCP. Das ciências sociais para ciências sociais em saúde: a produção científica em pós-graduação em ciências sociais. Ciênc Saúde Colet 2003; 8:275-85.

16. Canesqui AM. Produção científica das ciências sociais e humanas em saúde e alguns significados. Saúde Soc 2012; 21:15-23.

17. Gomes MHA, Goldenberg P. Retrato quase sem retoques dos egressos dos programas de pós-graduação em Saúde Coletiva, 1998-2007. Ciênc Saúde Colet 2010; 15:1989-2005.

18. Russo JA, Carrara SL. Sobre as ciências sociais na Saúde Coletiva - com especial referência à Antropologia. Physis (Rio J.) 2015; 25:467-84. 
19. Nunes JA. Um discurso sobre as ciências 16 anos depois. In: Santos BS, organizador. Conhecimento prudente para uma vida decente. Rio de Janeiro: Cortez Editora; 2006. p. 59-84.

20. Bourdieu P. Homo academicus. Florianópolis: Editora da UFSC; 2013.

21. Bourdieu P. Intelectuales, política y poder. Buenos Aires: Eudeba; 2014.

22. Knauth DR, Leal AF. A expansão das Ciências Sociais na Saúde Coletiva: usos e abusos da pesquisa qualitativa. Interface (Botucatu) 2014; 18:457-67.

23. Deslandes SF, Iriart JAB. Usos teórico-metodológicos das pesquisas na área de Ciências Sociais e Humanas em Saúde. Cad Saúde Pública 2012; 28:2380-6.

24. Bosi MLM. Pesquisa qualitativa em saúde coletiva: panorama e desafios. Ciênc Saúde Colet 2012; 17:575-86.

25. Luz MT. Complexidade do campo da Saúde Coletiva: multidisciplinaridade, interdisciplinaridade, e transdisciplinaridade de saberes e práticas - análise sócio-histórica de uma trajetória paradigmática. Saúde Soc 2009; 18:304-11.
26. Gomes MHA, Silveira C. Sobre o uso de métodos qualitativos em Saúde Coletiva, ou a falta que faz uma teoria. Rev Saúde Pública 2012; 46:160-5.

27. Nunes ED, Ferreto L, Oliveira ALO, Nascimento JL, Barros NF, Castellanos MEP. O campo da Saúde Coletiva na perspectiva das disciplinas. Ciênc Saúde Colet 2010; 15:1917-22.

28. Barata RB, Goldbaum M. Perfil dos pesquisadores com bolsa de produtividade em pesquisa do $\mathrm{CNPq}$ da área de saúde coletiva. Cad Saúde Pública 2003; 19:1863-76.

29. Ferreira J, Brandão ER. Desafios da formação antropológica de profissionais de saúde: uma experiência de ensino na pós-graduação em Saúde Coletiva. Interface (Botucatu) 2019; 23:e170686.

30. Minayo MCS. A produção de conhecimentos na interface entre as ciências sociais e humanas e a saúde coletiva. Saúde Soc 2013; 22:21-31.

31. Deslandes S, Maksud I. Capitais científicos em saúde coletiva: proposta de análise inspirada nas fontes utilizadas na obra Homo Academicus. Saúde Soc 2019; 28:324-36. 


\section{Abstract}

The contributions by Human and Social Sciences in Health (HSSH) have been decisive for dealing with the social dynamics involving human life, suffering, and illness. Thus, analysis of the configuration of the HSSH field has been a key research theme for many Brazilian authors. This article analyzes training in HSSH (with a special focus on research training) in graduate studies programs in Public Health from 2002 to 2016, considering the course supply in HSSH and the courses involving methodological training, based on their size, frequency, and principal theoretical and methodological influences. Our source was the files of "Disciplines" and "Program Proposals" in the Indicator Notebooks from the Brazilian Graduate Studies Coordinating Board (CAPES) and Sucupira databases. The syllabuses were read and analyzed for their themes, objectives, bibliographies, and authors. Data were recorded on an Excel spreadsheet and analyzed with the R statistical package. The results show stability in the course supply in HSSH (some 20\% over the period), but a modest presence of methodological courses in Social Sciences. We found a diversity of theoretical and methodological references, especially compilation works or didactic texts. We highlight the lack of classic texts and authors in the Social Sciences. The conclusions point to the challenge of transposing operative training, which allows instrumentally executing highly relevant research for health, but which can affect the potential for consolidation and theoretical innovation in social thinking in health.

Health Postgraduate Programs; Social Sciences; Humanities

\section{Resumen}

Las contribuciones de las Ciencias Sociales y Humanas en Salud (CSHS) han sido decisivas para tratar las dinámicas sociales que implican la vida, el sufrimiento y la enfermedad humanos. De esta forma, el análisis de la conformación del campo de las CSHS ha sido un tema de investigación de muchos autores brasileños. Este artículo analiza la formación en CSHS (con especial énfasis para la formación en investigación) en los programas de posgrado en Salud Colectiva durante el periodo de 2002 a 2016, considerando la oferta de las disciplinas de CSHS y las disciplinas de formación metodológica, a partir de su magnitud, frecuencia $y$ principales influencias teórico-metodológicas. Utilizamos como fuente los archivos de "Disciplinas" y "Propuesta del Programa" que integran los Cuadernos de Indicadores del banco de datos de la Coordinación de Perfeccionamiento de Personal de Nivel Superior (CAPES) y de la base Sucupira. Los programas fueron leídos y analizados considerando sus temáticas, objetivos, obras y autores. Los datos fueron registrados en plantilla de Excel y analizados con la ayuda del programa estadistico $R$. Los resultados muestran la estabilidad de la oferta de las disciplinas de CSHS (cerca de un 20\% a lo largo de todo el período), pero una modesta presencia de disciplinas de metodología en Ciencias Sociales. Se percibe la diversidad de referencias teórico-metodológicas, con especial relevancia para obras de compilaciones o textos didácticos. Se destaca la ausencia de los textos y de los autores clásicos de las Ciencias Sociales. Las conclusiones apuntan al desafio de transposición de la formación operativa, que permite ejecutar instrumentalmente investigaciones de alta relevancia temática para la salud, pero que puede afectar el potencial de consolidación e innovación teórica del pensamiento social en salud.

Programas de Posgrado en Salud; Ciencias Sociales; Humanidades
Recebido em 17/Jul/2019

Versão final reapresentada em 30/Out/2019

Aprovado em 06/Nov/2019 